\title{
ANÁLISE DOS EFEITOS DOS TRATAMENTOS TÉRMICOS DE TÊMPERA E PARTICIONAMENTO, NA MICROESTRUTURA E PROPRIEDADES MECÂNICAS DE TRÊS AÇOS C-MN DE APLICAÇÃO API
}

\author{
Amanda de Paiva Silva ' \\ Luiz Cláudio Cândido ${ }^{2}$ \\ Vicente Braz Trindade ${ }^{2}$ \\ Paulo Henrique Grossi Dornelas ${ }^{3}$
}

\section{Resumo}

Os tratamentos térmicos de têmpera e particionamento (Q\&P) vem sendo largamente estudados, uma vez que tem sido relatado na literatura uma melhora nas propriedades mecânicas dos aços após esses tratamentos. Busca-se, então, analisar os efeitos do mesmo, em aços API usados no revestimento de poços de petróleo; e na condução de óleo e gás (aço API 5CT e aço API 5L, respectivamente). Esses tratamentos têm como objetivo a formação de uma microestrutura que consiste, normalmente, numa matriz martensítica com considerável teor de austenita retida $\left(\gamma_{R}\right)$. Desta forma, foi desenvolvida uma rota de tratamentos Q\&P, empregando-se diferentes temperaturas de particionamento, em três aços API com aplicações na indústria petrolífera. As influências desses tratamentos nas propriedades mecânicas dos aços foram analisadas, via ensaios de tração, impacto Charpy e microdureza Vickers, e comparadas com os resultados obtidos ao se utilizar a rota habitual de tratamentos térmicos, de têmpera e revenimento (Q\&T). Foram observadas melhoras na ductilidade, razão elástica e tenacidade ao impacto dos aços.

Palavras-chave: Aço API 5CT; Aço API 5L; Têmpera e particionamento; Microestrutura e propriedades mecânicas.

\section{ANALYSIS OF THE EFFECTS OF THE THERMIC TREATMENT OF QUENCHING AND PARTITIONING, ON THE MICROSTRUCTURE AND MECHANICAL PROPERTIES OF THREE C-MN STEELS APPLIED AS API}

\begin{abstract}
The thermic treatments of quenching and partitioning (Q\&P) are being widely studied, hence it has been documented an improvement in the mechanical properties of steels. Therefore, it is interesting to analyze the effects of these treatments in API steels utilized in the drilling of pitches; and in the transport of oil and gas (API 5CT and API 5L, respectively). These treatments normally result in a microstructure composed of a martensitic matrix with some retained austenite $\left(\gamma_{R}\right)$. Therefore, it was developed a thermic treatment route, on three API steels with application in the oil industries. The influences of these treatments on the mechanical properties of the steels were analyzed using tensile tests, Charpy impact and Vickers microhardness and were compared with the results from the traditional route of thermic treatments of quenching and tempering (Q\&T). It was observed some improvements in the ductility, elastic ratio and impact toughness of the steels. Keywords: API 5CT steels; API 5L steels; Quenching and partitioning; Microstructure and mechanical properties.
\end{abstract}

\section{INTRODUÇÃO}

Uma nova rota de tratamentos térmicos, proposta por Speer et al. [I] e denominada de têmpera e particionamento vem sendo cada vez mais estudada, uma vez que permite a obtenção de uma microestrutura composta por uma matriz martensítica com considerável quantidade de austenita retida. Esse tratamento consiste em promover um

IUniversidade Federal de Ouro Preto - UFOP, Ouro Preto, MG, Brasil. E-mail: eng.amandapaiva@gmail.com ${ }^{2}$ Departamento de Engenharia Metalúrgica, Universidade Federal de Ouro Preto - UFOP, Ouro Preto, MG, Brasil ${ }^{3}$ Universidade Federal do Rio de Janeiro - UFRJ, Rio de Janeiro, RJ, Brasil 
resfriamento rápido do material, a partir da temperatura de austenitização $\left(T_{A}\right)$, até uma temperatura $T_{Q}$, que se encontra no intervalo de início e fim da formação da martensita ( $M_{\mathrm{f}}$ e $\mathrm{M}_{\mathrm{f}}$, respectivamente), sendo que durante esta etapa, a microestrutura é parcialmente transformada em martensita primária $\left(\alpha_{\mathrm{p}}^{\prime}\right)$. Em seguida, promove-se um reaquecimento até a temperatura de particionamento $\left(T_{p}\right)$, por um certo tempo, onde ocorre uma difusão de carbono a partir da $\alpha_{p}^{\prime}$ supersaturada, para a austenita não transformada $\left(\gamma_{R}\right)$. Assim, a $\gamma_{R}$ torna-se enriquecida em carbono e metaestável a temperatura ambiente. Após o particionamento, promove-se o resfriamento final em água. Deve-se, contudo, garantir que $\gamma_{R}$ esteja suficientemente enriquecida em carbono, para que esta não se decomponha em martensita ou bainita secundárias ( $\alpha_{S}^{\prime}$ e $B_{s}$, respectivamente), ao término dos tratamentos Q\&P. A microestrutura formada permite a combinação de alta resistência mecânica e dureza, devido à matriz martensítica, aliados a boa ductilidade e tenacidade ao impacto, devido à austenita retida [2,3]. Na Figura I tem-se uma representação esquemática dos tratamentos Q\&P.

Três condições de equilíbrio devem ser consideradas para que ocorra o particionamento de carbono da martensita para a austenita, estas, chamadas de condições de equilíbrio constrito de carbono (ECC): (I) supressão da formação de carbonetos; (2) mesmo potencial químico com relação ao carbono, na martensita e na austenita; (3) interface estacionária entre a martensita e a austenita $[1,3,4]$. Uma vez que durante os tratamentos Q\&P as temperaturas são relativamente brandas, considera-se que não ocorreu particionamento de ferro ou outros elementos substitucionais [3].

Em seu estudo, Santofimia et al. [5] analisaram um aço TRIP atacado empregando-se reagente Le Pera. Foi observado a formação de ilhas claras formadas por martensita não temperada e austenita retida, que eram claramente distintas da ferrita, enquanto que a bainita e a martensita temperada apresentavam coloração escura. Além disso os autores perceberam que durante o particionamento, empregando-se tempos mais longos, a decomposição da austenita em bainita superior, leva a um aumento no teor de carbono de $\gamma_{R}$ e a um decréscimo em sua fração volumétrica.

Considerando-se que existe uma demanda constante das indústrias em se produzir aços mais baratos, os tratamentos Q\&P podem representar uma alternativa aos tratamentos térmicos convencionais. Uma vez que possibilitam a obtenção de aços com boa combinação de resistência mecânica e ductilidade. Dessa forma, é possível uma redução nos custos de fabricação, já que os tubos podem ser confeccionados com paredes mais finas e há possibilidade de se empregarem menos etapas durante seu processamento. Além disso, os gastos com relação ao transporte desses materiais até os locais de extração de petróleo, seriam menores devido a diminuição da espessura dos tubos, sem, contudo, comprometer a segurança e a qualidade dos mesmos.

Nesse trabalho, analisaram-se os efeitos dos tratamentos Q\&P na microestrutura e propriedades mecânicas de três aços muito utilizados pela indústria petrolífera. A fim de revelar a microestrutura, e especificamente, microconstituintes enriquecidos em carbono, como a $\gamma_{R}$ e o constituinte martensita/austenita retida (MA), empregaram-se dois reagentes de ataque químico, Nital $2 \%$ e Le Pera. Foram realizados ensaios de tração, impacto Charpy e microdureza Vickers para verificar as propriedades mecânicas. Por fim, compararam-se os resultados obtidos com os de tratamentos térmicos convencionais, de têmpera e revenimento.

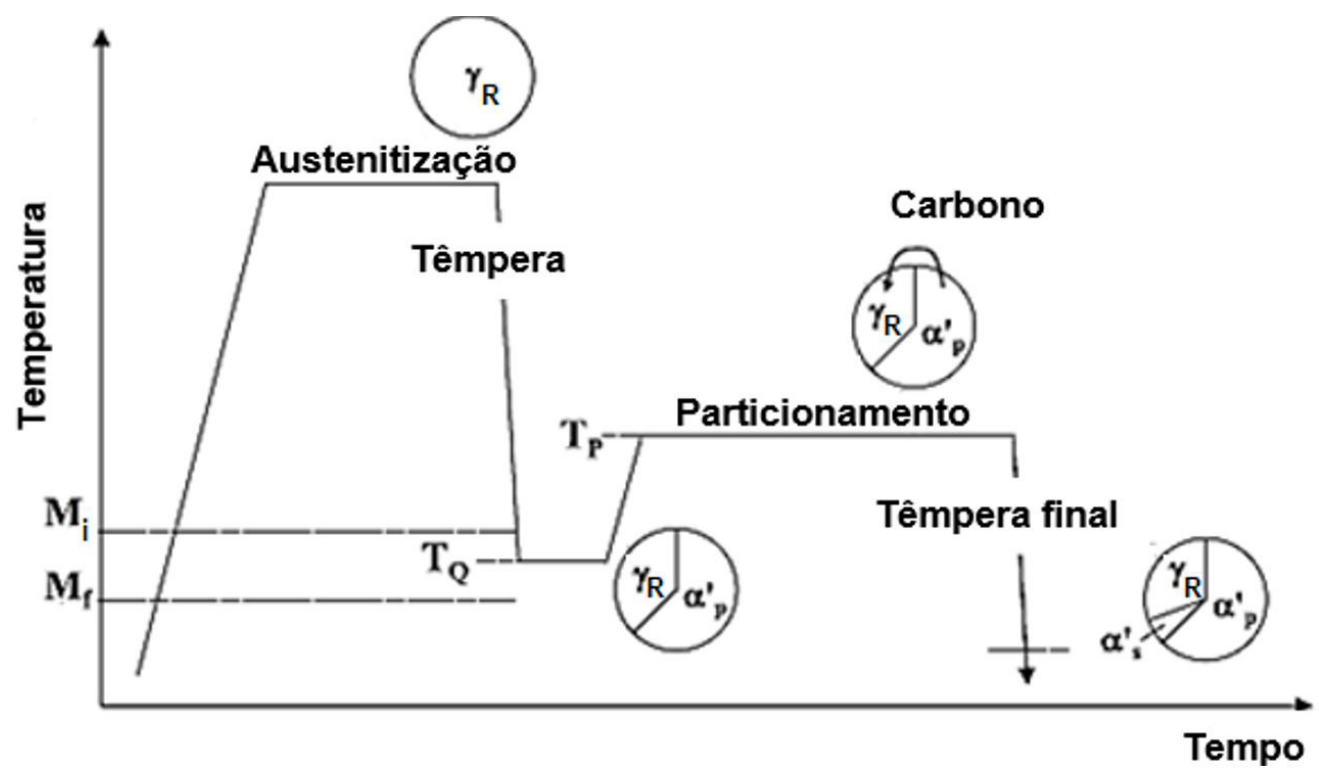

Figura I. Representação esquemática dos tratamentos Q\&P. $\gamma_{R}$ - austenita retida, $\alpha_{P}^{\prime}-$ martensita primária, $\alpha_{S}^{\prime}-$ martensita secundária [2]. 


\section{PARTE EXPERIMENTAL}

\section{I Materiais}

Analisaram-se três tubos de aço C-Mn (aço A, B e C) com aplicaçóes API, normalmente empregados no revestimento dos poços de exploração de petróleo (API 5CT, aço C) e na construção de dutos para condução de óleo e gás (API 5L, aço A e B). Esses tubos apresentavam diferentes teores de carbono. Possuíam diâmetro externo de $273 \mathrm{~mm}$ e 12,7mm de espessura de parede, e foram seccionadas em chapas. Na Tabela I apresenta-se a composição nominal dos aços estudados.

\subsection{Metodologia}

Para a realização dos tratamentos Q\&P foi preciso confeccionar uma cuba de aço com as dimensões $300 \mathrm{~mm} \times 200 \mathrm{~mm} \times 200 \mathrm{~mm}$. Esta, foi posicionada no interior de um dos fornos (tipo mufla), que teve sua temperatura ajustada para $350^{\circ} \mathrm{C}$. Como sal de têmpera, empregou-se nitrato de sódio $\left(\mathrm{NaNO}_{3}\right)$, uma vez que apresenta temperatura de fusão de $310^{\circ} \mathrm{C}$, e encontra-se no intervalo de temperaturas $M_{i}$ e $M_{f}$ dos aços do estudo. A temperatura do banho foi monitorada por um termopar do tipo K, posicionado no interior do banho.

\subsection{Tratamentos térmicos}

Na Figura 2 apresentam-se os diagramas de fase TRC para os aços estudados. Em (a) são apresentadas as curvas de resfriamento contínuo para os aços $A$ e $B$ e em (b), está representado o diagrama $T R C$ do aço $C$, onde: $F G$ trata-se da ferrita de contorno de grão; $F Q P$ é a ferrita quase poligonal; FP representa a ferrita poligonal; FB representa a ferrita bainítica; $P$ trata-se da perlita e $B$ representa a bainita.

Para realização do tratamento $\mathrm{Q} \& \mathrm{~T}$, as chapas foram completamente austenitizadas, a temperatura de $900^{\circ} \mathrm{C}$, por 15 minutos, com têmpera subsequente em água. Em seguida, foram reaquecidas até o patamar de revenimento a $650^{\circ} \mathrm{C}$, durante 40 minutos. O resfriamento final se deu ao ar calmo.

Para o tratamento Q\&P, as chapas de cada um dos aços foram resfriadas, a partir da temperatura de austenitização de $900^{\circ} \mathrm{C}$, sendo para tal, imersas no banho de sal fundido de $\mathrm{NaNO}_{3}$, onde sofreram têmpera parcial até a temperatura de $350^{\circ} \mathrm{C}$, e foram mantidas nesse, por 5 minutos. Em seguida, foram reaquecidas até o patamar de particionamento de $500^{\circ} \mathrm{C}$, por 20 minutos, com têmpera final, em água. Na Figura 3 apresenta-se os ciclos dos tratamentos térmicos empregados, sendo (a), referente ao tratamento Q\&T e (b), referente ao tratamento Q\&P.

Ressalta-se que as temperaturas de revenimento/particionamento foram arbitrarias, a fim de verificar os efeitos dos tratamentos Q\&P, sobre aços

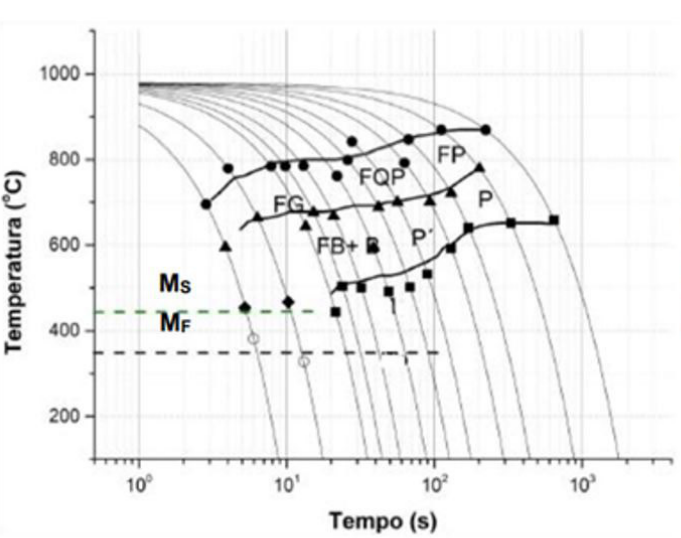

(a)

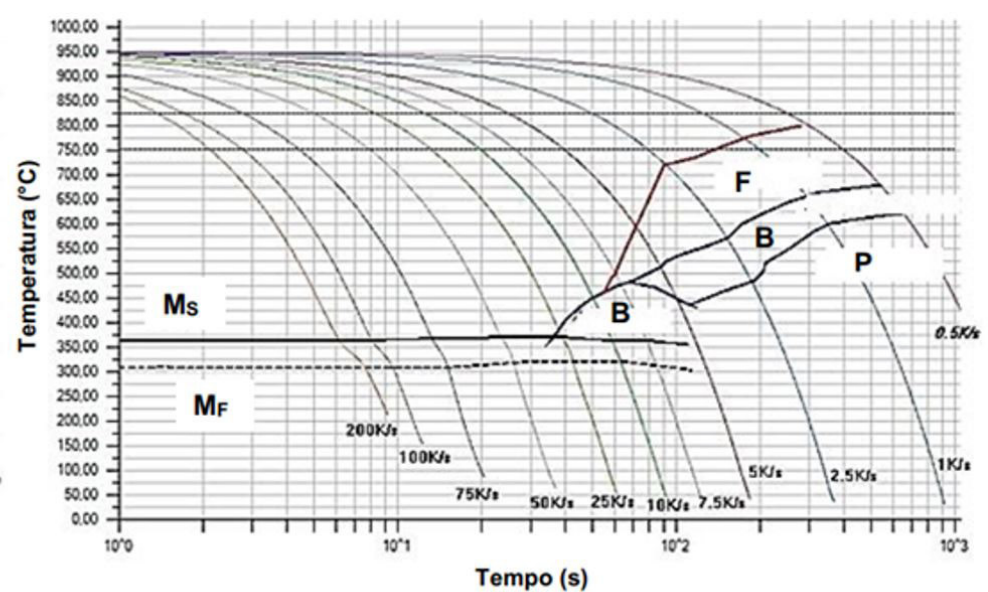

(b)

Figura 2. Diagramas TRC empregados para a determinação das transformações de fase esperadas para (a) aços $A$ e $B$; (b) aço $C$, onde, F: ferrita; FG: ferrita granular; FQP: ferrita quase poligonal; FP: ferrita poligonal; FB: ferrita bainítica; P: perlita e B: bainita. Fonte: Trindade (relatório confidencial).

Tabela I. Composição química nominal dos aços C-Mn, empregados no estudo (\% em massa)

\begin{tabular}{cccccccc}
\hline $\begin{array}{c}\text { Amostra } \\
(\mathbf{A c ̧ o})\end{array}$ & $\mathbf{C}_{\text {max }}$ & $\mathbf{S i}_{\text {max }}$ & $\mathbf{M n}_{\text {max }}$ & $\mathbf{C r}_{\text {max }}$ & $\mathbf{A l}_{\text {má }}$ & $\mathbf{B}_{\text {má }}$ & $\mathbf{T i}+\mathbf{N b}+\mathbf{V}$ \\
\hline $\mathbf{A}$ & 0,10 & 0,27 & 1,80 & 0,16 & 0,04 & 0,0005 & $\leq 0,07$ \\
$\mathbf{B}$ & 0,20 & 0,27 & 1,80 & 0,24 & 0,04 & 0,0005 & $\leq 0,07$ \\
$\mathbf{C}$ & 0,27 & 0,35 & 1,80 & 0,44 & 0,04 & 0,0020 & $<0,08$ \\
\hline
\end{tabular}

Fonte: VSB. 


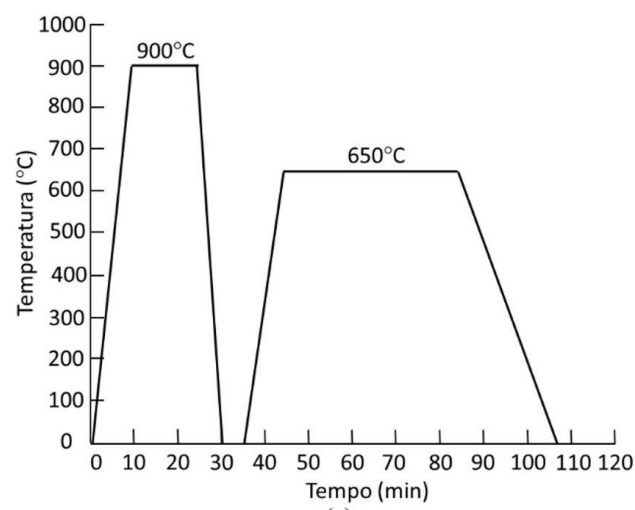

(a)

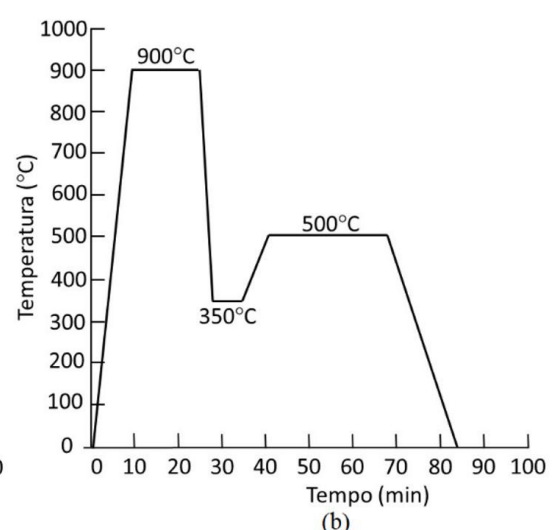

(b)

Figura 3. Representação esquemática dos tratamentos térmicos desenvolvidos, com as respectivas temperaturas dos patamares isotérmicos. (a) Q\&T; (b) Q\&P.

Tabela 2. Parâmetros dos tratamentos Q\&T e Q\&P empregados nas amostras BQT e BQP

\begin{tabular}{|c|c|c|c|c|c|c|}
\hline \multirow{3}{*}{$\begin{array}{c}\text { Amostra } \\
\text { BQT }\end{array}$} & \multicolumn{6}{|c|}{ Têmpera e Revenimento } \\
\hline & \multicolumn{2}{|c|}{ Austenitização } & \multirow{2}{*}{\multicolumn{2}{|c|}{$\begin{array}{c}\text { Têmpera } \\
\text { em água }\end{array}$}} & \multicolumn{2}{|c|}{ Revenimento } \\
\hline & $\mathrm{T}\left({ }^{\circ} \mathrm{C}\right)$ & $\mathrm{t}(\mathrm{min})$ & & & $\mathrm{T}\left({ }^{\circ} \mathrm{C}\right)$ & $\mathrm{t}(\mathrm{min})$ \\
\hline & 920 & 10 & & & 650 & 30 \\
\hline \multirow{2}{*}{ Amostra } & \multicolumn{6}{|c|}{ Têmpera e Particionamento } \\
\hline & \multicolumn{2}{|c|}{ Austenitização } & \multicolumn{2}{|c|}{ Resfriamento* } & \multicolumn{2}{|c|}{ Particionamento } \\
\hline \multirow[t]{2}{*}{ BQP } & $\mathrm{T}\left({ }^{\circ} \mathrm{C}\right)$ & $\mathrm{t}(\mathrm{min})$ & $\mathrm{T}\left({ }^{\circ} \mathrm{C}\right)$ & $\mathrm{t}(\mathrm{min})$ & $\mathrm{T}\left({ }^{\circ} \mathrm{C}\right)$ & $\mathrm{t}(\mathrm{min})$ \\
\hline & 920 & 10 & 350 & 5 & 650 & 30 \\
\hline
\end{tabular}

com aplicação API, uma vez que ainda não estão muito documentados na literatura. Além disso, buscando-se avaliar os efeitos das temperaturas de austenitização e de particionamento na microestrutura, repetiram-se os tratamentos Q\&P, no aço com menor teor de carbono (amostra B). Na Tabela 2, detalha-se os parâmetros do tratamento Q\&T (amostra BQT, para comparação) e Q\&P (amostra BQP) analisados nesta etapa.

\subsubsection{Ensaios mecânicos e análises microestruturais}

As propriedades mecânicas foram analisadas a partir de ensaio de tração (EMIC $1.000 \mathrm{kN}$, modelo $\mathrm{DL})$; impacto Charpy a $-60^{\circ} \mathrm{C}$ (Instron 406,7], modelo SI- ID3); e microdureza Vickers (EMCOTEST, modelo Duravision 250), utilizando a carga de $1.000 \mathrm{gf}$ por 10 segundos. Para as análises microestruturais foram empregados dois reagentes químicos diferentes, Nital $2 \%$ e reagente Le Pera (para amostras submetidas aos tratamentos Q\&P).

\section{RESULTADOS E DISCUSSÃO}

\section{I Análises Microestruturais}

$\mathrm{Na}$ Figura 4 apresentam-se as microestruturas do aço $A$ (MEV), submetidas aos tratamentos (a) Q\&T, (b) Q\&P (Nital 2\%) e (c) Q\&P (Le Pera). Pode-se perceber que as microestruturas formadas em ambos os tratamentos são similares. Em (a) a microestrutura é composta por bainita revenida (B'); em (b) observa-se a presença de ferrita (F) e bainita; enquanto que em (c), supõe-se que o grão não atacado (alto relevo) corresponda a $\gamma_{R}$, apesar de ser difícil realizar corretamente sua diferenciação com relação ao constituinte MA. Acredita-se, entretanto, que parte $\gamma_{R}$ deve ter se decomposto em $B_{S}$ uma vez que, provavelmente, a mesma, não tenha sido suficientemente enriquecida em carbono. As diferenças observadas entre (b) e (c) devem-se aos reagentes de ataque químico agirem, preferencialmente, em áreas diferentes da microestrutura [6]. Quanto ao aço $B$, foi formado bainita primária $(B)$, secundária $\left(B_{s}\right)$ e constituinte MA após os tratamentos Q\&P; enquanto que o aço $C$, possui uma matriz composta por $\alpha_{p}^{\prime}$ ' majoritariamente, além apresentar um constituinte com coloração mais clara que pode tratar-se de martensita secundária $\left(\alpha_{s}^{\prime}\right), B_{s}$ ou mesmo, constituinte MA. Acredita-se se tratar do constituinte MA, devido aos resultados dos ensaios mecânicos obtidos (tração e impacto, 3.2). Tais resultados estão de acordo com o obtido por $[7,8]$.

\subsection{Ensaios Mecânicos}

\subsection{Ensaio de tração}

Os resultados obtidos, em relação ao limite de escoamento (LE), limite de resistência (LR), bem como a variação da razão elástica (LE/LR) para os tratamentos Q\&P, foram comparados com os valores obtidos para os corpos 
de prova que sofreram o tratamento Q\&T, como pode-se observar na Figura 5. Em (a) têm-se os resultados do ensaio de tração, com relação aos valores de LE e $L R$, nas condições Q\&T e Q\&P; e em (b) está representada a razão elástica.

Os resultados de LE e LR para os aços na condição Q\&P, apresentam valores menores quando comparados, com a condição Q\&T. Além disso, o LE das amostras tratadas por Q\&P diminui com o aumento do teor de carbono dos aços. Esse resultado é provavelmente devido às microestruturas formadas. Nos aços B e C, observaram-se estruturas secundárias, como $B_{s}$ e $\alpha_{s}^{\prime}$, que causaram variações significativas quanto ao $L R$ no aço $C$, onde provavelmente esses constituintes foram gerados em maior quantidade.

Segundo Mandal et al. [7] a diminuição da resistência mecânica dos aços tratados por Q\&P e sua maior ductilidade, pode ser atribuído à combinação de diversos fatores como: diminuição na supersaturação em carbono da martensita; variações na densidade de discordâncias; presença de ferrita na microestrutura final do aço (como observado nas amostras do aço A); e aumento na fração de austenita retida, enriquecida em carbono. Além disso, como as condições de têmpera são mais severas nos tratamentos Q\&T, a formação da martensita é favorecida.
A razão elástica (LE/LR), também é um parâmetro importante a ser analisado, quanto a aplicabilidade dos tratamentos de Q\&P, pois o efeito mola, está diretamente ligado a esta relação. Esse fenômeno indesejável ocorre, quando a chapa que está sendo conformada, "salta da matriz" por não assumir o formato desejado, diminuindo a capacidade do material de tolerar deformações plásticas [8,9]. Dessa forma, quanto mais baixos os valores da razão elástica, maior a capacidade de encruamento do material, e consequentemente, menor a probabilidade do surgimento desse efeito durante a conformação do tubo. Então, pode-se perceber a partir da Figura 5b, que a condição Q\&P foi benéfica para os aços nesse sentido.

Em seguida analisaram-se as amostras $B Q P$ que foram tratadas via Q\&P. Na Figura 6 observa-se um aumento na ductilidade dos aços submetidos aos tratamentos Q\&P, com um alongamento de aproximadamente $4 \%$ quando comparados aos tratamento Q\&T. Pode-se justificar esse aumento pela a ocorrência do Efeito TRIP, no qual parte da $\gamma_{R}$ transforma-se em martensita, devido a aplicação de uma tensão externa. Efeito esse, que gera uma diminuição das tensões residuais localizadas do material, devido a esta transformação de fase [10]. Tal resultado, está de acordo

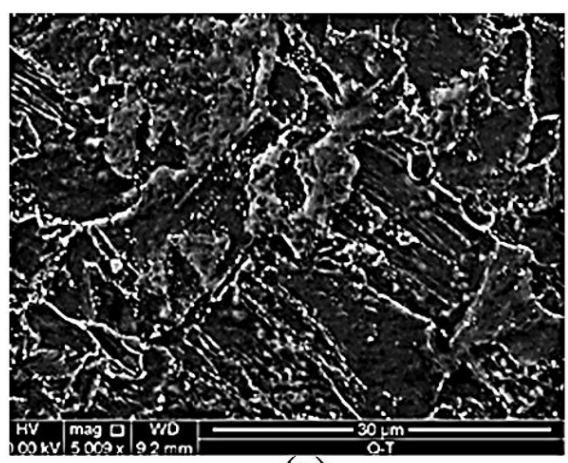

(a)

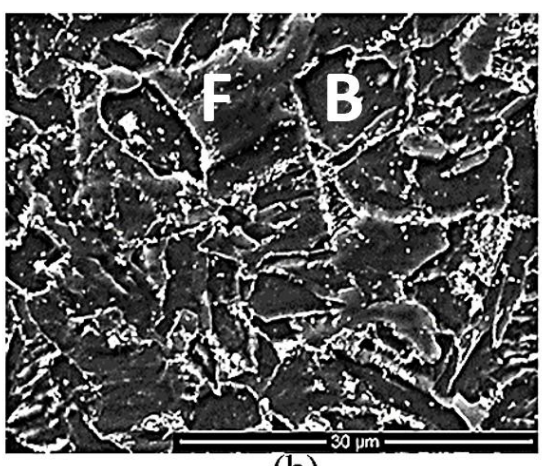

(b)

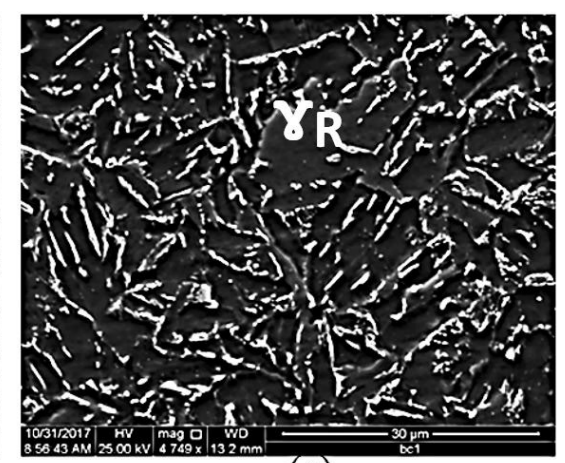

(c)

Figura 4. Microestruturas do aço C-Mn A após os tratamentos (a) Q\&T, (b) Q\&P (nital 2\%) (c) Q\&P (Le Pera).

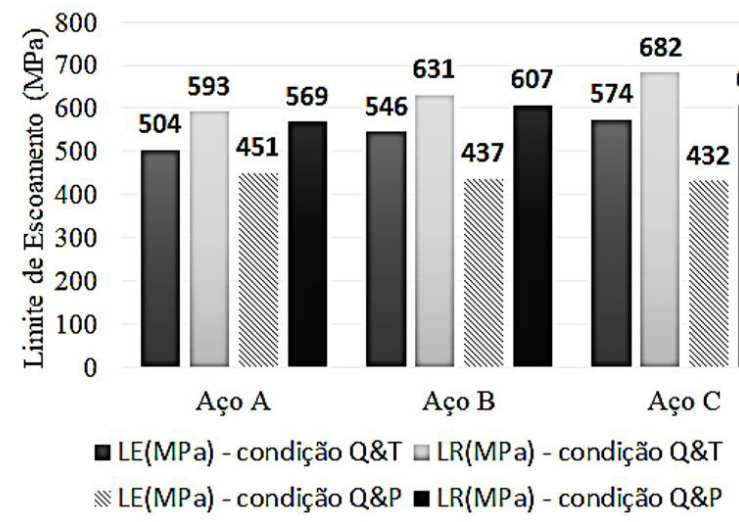

(a)

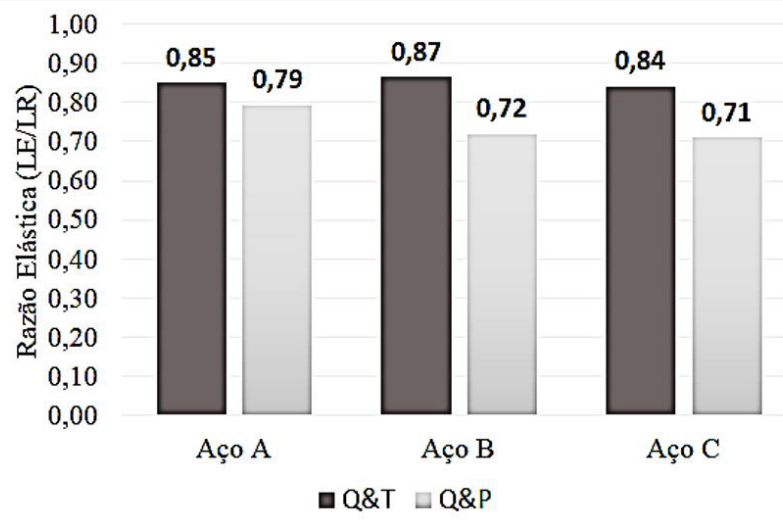

(b)

Figura 5. (a) Resistência mecânica; (b) Razão elástica (LE/LR); obtidas para as amostras dos aços C-Mn A, B e C. submetidas aos tratamentos Q\&T e Q\&P. 
com o proposto por [II, I2]. Além disso, esse ganho na ductilidade é muito benéfico para aços com aplicação API, uma vez que no processo de lançamento de dutos submarinos pelo método reeling ocorre um aumento na

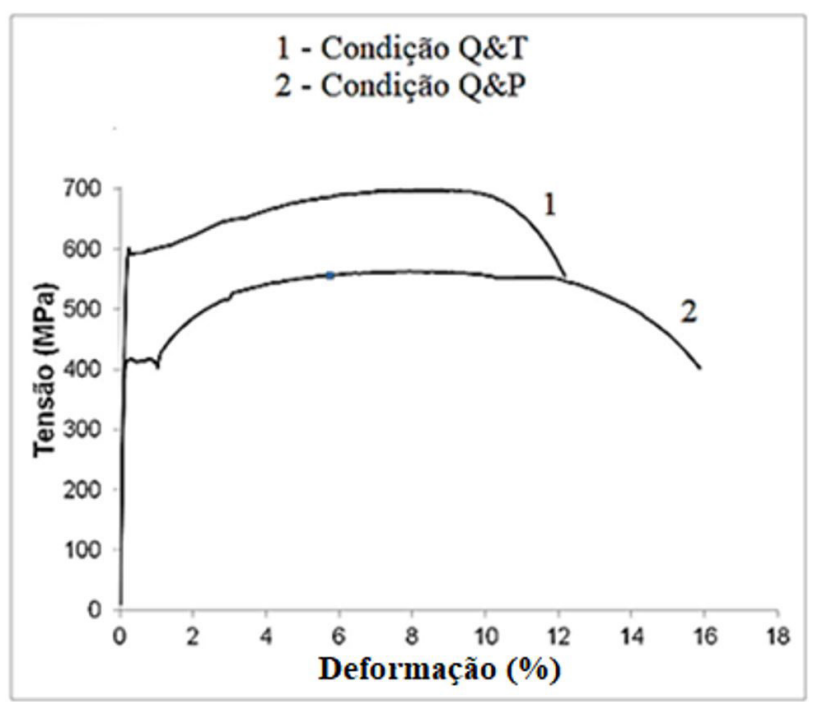

Figura 6. Curvas de tensão $x$ deformação obtidas para as amostras $\mathrm{BQT}$ e BQP, submetidas aos tratamentos Q\&T e Q\&P, respectivamente; aço C-Mn B.

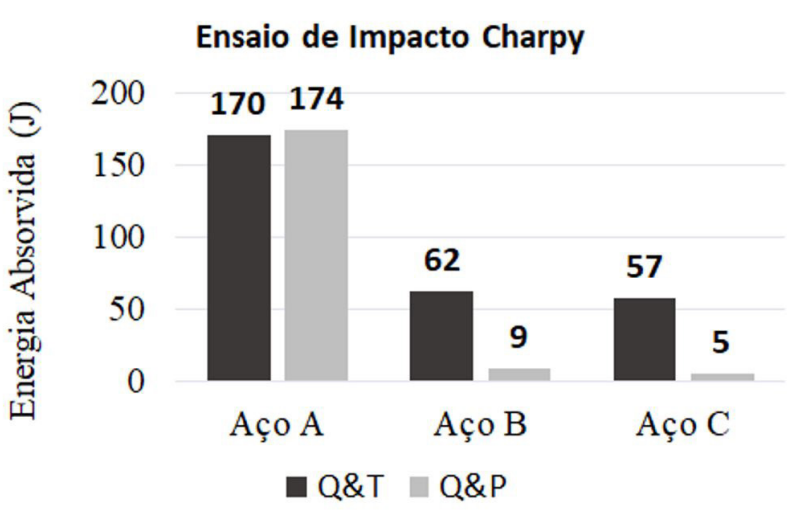

Figura 7. Resistência ao impacto a temperatura de $-60^{\circ} \mathrm{C}$, das amostras dos aços C-Mn A, B e C, submetidas aos tratamentos Q\&T e Q\&P. resistência mecânica do aço, com consequente redução na ductilidade [13].

\subsubsection{Ensaio de impacto Charpy}

A partir da Figura 7, percebe-se que os tratamentos Q\&P melhoraram um pouco a tenacidade ao impacto do aço $A$, enquanto que para os aços $B$ e $C$, a mesma apresentou-se muito inferior. Esse efeito pode ser atribuído à presença de $B_{S}$ (aço $B$ ) e $\alpha_{S}^{\prime}$ (aço $C$ ) além desses aços apresentarem maior teor de carbono, e o constituinte MA (possivelmente formado) em suas microestruturas. Essas fases são formadas pela decomposição da $\gamma_{R}$, devido ao particionamento de carbono não ter sido suficiente para promover a estabilização da mesma, sendo que possuem baixa tenacidade ao impacto, diminuindo a energia absorvida. Além disso, a microestrutura formada no aço $A$ é composta por $F$ e $B$, e foi observada a presença de $\gamma_{R}$, que aumenta a tenacidade ao impacto do mesmo [I-3], evidenciando uma melhoria no comportamento desse aço quando submetido ao tratamento proposto, sendo esse um dos objetivos dos tratamentos térmicos de têmpera e particionamento.

O aumento observado quanto à tenacidade ao impacto do aço $A$, pode ser explicado, já que no ensaio de impacto parte da energia potencial, devido ao movimento do martelo, é absorvida pelo o material e provoca uma transformação de fase, da austenita em martensita. Esta transformação é denominada de Efeito TRIP e causa um relaxamento das tensões residuais locais. Além disso, a transformação de fase pode ocorrer de forma localizada na ponta de eventuais trincas, podendo inclusive ser gerada pela deformação que a própria trinca causa no material. Dessa forma, a energia necessária para promover a falha do aço é maior $[10,14]$.

Analisaram-se então, as amostras BQT e BQP, quanto à tenacidade ao impacto. Apresentam-se tais resultados na Figura 8, na forma de energia absorvida (J) em função da Temperatura $\left({ }^{\circ} \mathrm{C}\right)$. Pode-se perceber que na condição Q\&P, no geral, a energia absorvida no ensaio de impacto foi maior que quando comparado à condição Q\&T, para temperaturas $\geq-20^{\circ} \mathrm{C}$, sendo que abaixo desta, o comportamento do material foi o inverso.

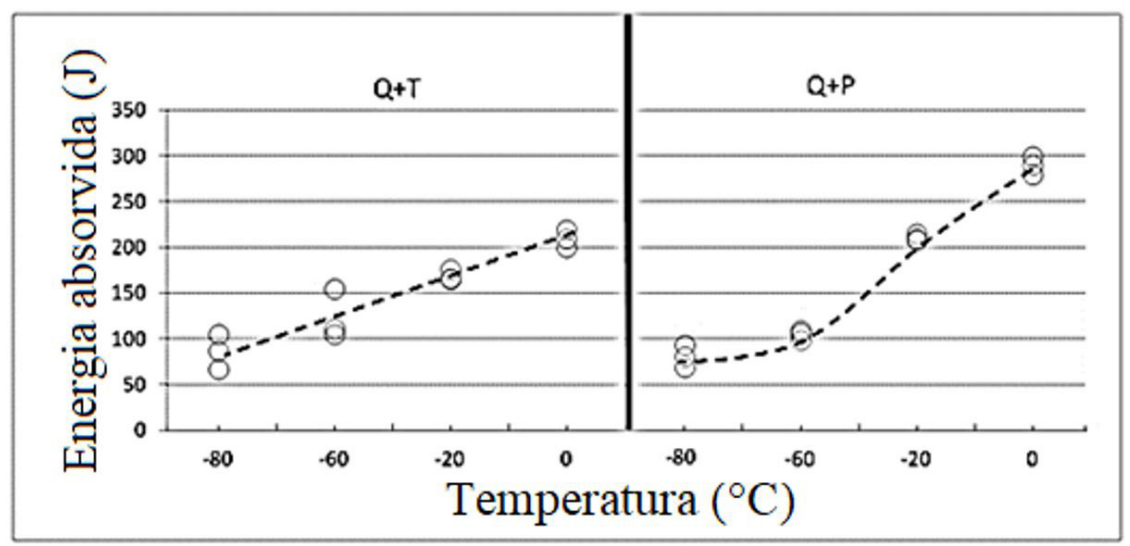

Figura 8. Energia absorvida $(\mathrm{J})$ no ensaio de impacto $x$ Temperatura $\left({ }^{\circ} \mathrm{C}\right)$ para as amostras $\mathrm{BQT}$ e BQP; aço C-Mn B. 


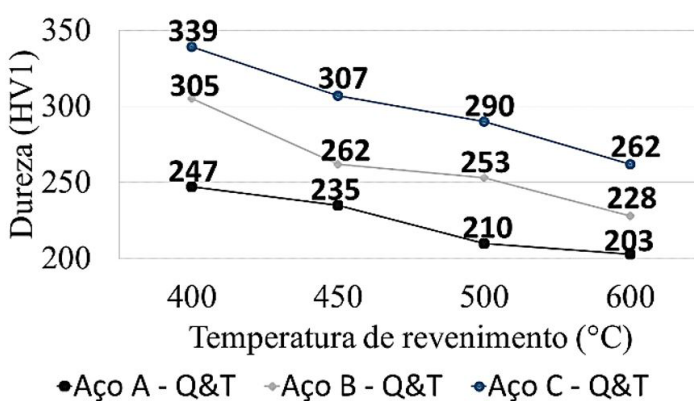

(a)

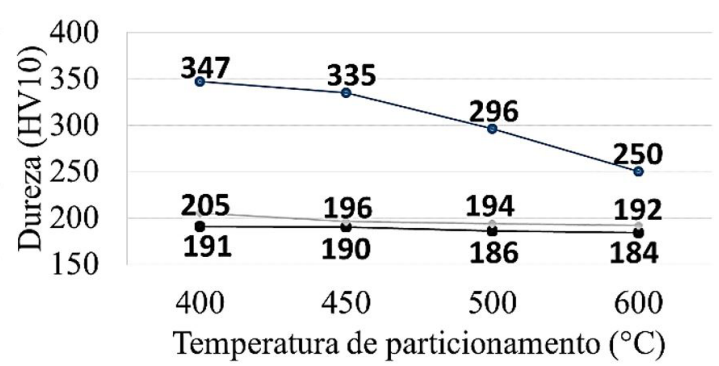

-Aço A - Q\&P -Aço B - Q\&P -Aço C - Q\&P

(b)

Figura 9. Dureza média em função de (a) temperatura de revenimento; (b) temperatura de particionamento, para tratamento de Q\&T e Q\&P, das amostras dos aços C-Mn A, B e C.

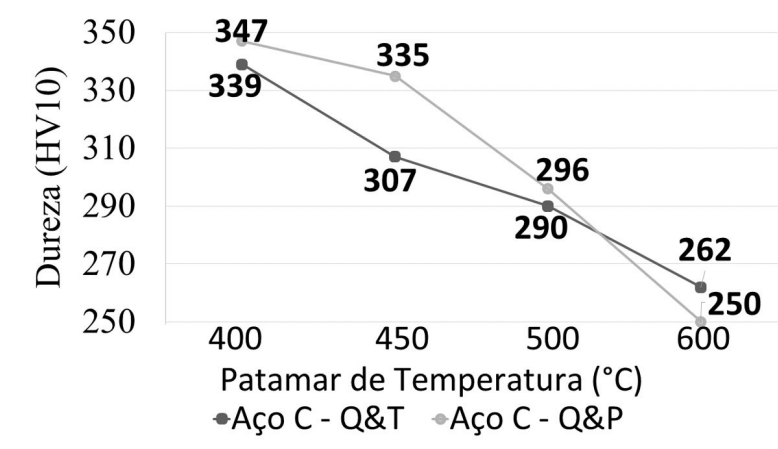

Figura 10. Dureza média em função patamar de temperatura das amostras do aço C-Mn C submetidas a Q\&T e Q\&P.

\subsubsection{Ensaio de microdureza Vickers}

As amostras dos aços A, B e C, submetidas a Q\&P, apresentaram tendências semelhantes às submetidas a $\mathrm{Q} \& T$, conforme pode ser observado na Figura 9. O aço com maior teor inicial de carbono (aço $\mathrm{C}$ ) apresentou valores mais altos no que diz respeito à dureza média. Justificam-se esses resultados, a partir das microestruturas observadas nos aços em questão após os tratamentos Q\&P, nas quais observou-se a presença de ferrita e bainita no aço $A$; e bainita no aço $B$ que possuem durezas menores que a martensita primária, formada no aço $C$.

A partir do comparativo entre as curvas de dureza do aço C, construiu-se o gráfico da Figura 10 para as condições Q\&T e Q\&P. Observa-se de acordo com a Figura 9, que - comportamento desse aço difere dos demais. Para os aços $A$ e $B$, a dureza média obtida após os tratamentos $Q \& T$, foi maior que a dureza média dos tratamentos Q\&P, em todas as temperaturas de particionamento. Entretanto, essa tendência não se manteve para o aço $C$, a temperaturas inferiores a $500^{\circ} \mathrm{C}$, onde apresenta maiores valores de dureza média, nos tratamentos térmicos de têmpera e particionamento. Esse fato pode estar relacionado à formação de martensita secundária, visto que, como proposto por [1-3], essa, apresenta maior conteúdo de carbono que a martensita primária, e dessa forma, maior dureza.

\section{CONCLUSÕES}

Revelaram-se as microestruturas formadas nos aços do estudo. No aço $A$, percebe-se a presença de ferrita, bainita e $\gamma_{R}$; no aço $B$, bainita primária e secundária, constituinte $M A$ e $\gamma_{R}$; e em C martensita primária e secundária, bainita secundária, constituinte $M A$ e $\gamma_{R}$.

Os tratamentos Q\&P conferiram aos aços menores valores, com relação à razão elástica de 0,$79 ; 0,72$ e 0,7I para os aços $A, B$ e C, respectivamente. Além disso, o tratamento Q\&P aumentou a deformação máxima das amostras BQP, em tração, em aproximadamente $4 \%$. A partir do ensaio de impacto Charpy percebe-se que o tratamento Q\&P melhorou a tenacidade ao impacto do aço A (I74 J). Para o aço $\mathrm{B} \mathrm{e} C$, entretanto, a presença dos constituintes secundários, aliadas ao constituinte MA, ofuscaram os efeitos benéficos da presença de $\gamma_{R}$. Com relação ao ensaio de microdureza Vickers, as amostras submetidas aos tratamentos Q\&P apresentaram um comportamento similar, às tratadas por Q\&T, com diminuição da dureza, quanto maior a temperatura do patamar de particionamento.

\section{Agradecimentos}

Os autores agradecem a UFOP e a empresa VSB para a realização desse trabalho, além da FAPEMIG pela concessão da bolsa.

\section{REFERÊNCIAS}

I Speer JG, Streicher AM, Matlock DK, Assunção FCR, Krauss G. Quenching and partitioning: a fundamentally new process to create high strength TRIP sheet microstructures. In: Proceedings of the Symposium on the Thermodynamics, Kinetics, Characterization and Modeling of Austenite Formation and Decomposition; Chicago, Illinois, USA; 2003 November 9- 12. Warrendale, Pa: TMS; 2003. p. 505-522. 
2 Seo EJ, Lawrence C, Cooman BC. Kinetics of the partitioning of carbon and substitutional alloying elements during quenching and partitioning (Q\&P) Processing of Medium Mn Steel. Acta Materialia. 2016;107:354-365.

3 Edmonds DV, He K, Rizzo FC, Cooman BC, Matlock DK, Speer JG. Quenching and partitioning martensite - a novel steel heat treatment. Materials Science and Engineering A. 2006;438:25-34.

4 Santofimia MJ, Zhao L, Petrov RH, Sietsma J. Characterization of the microstructure obtained by the Q\&P process in a low carbon steel. Materials Characterization. 2008;59:1758-1764.

5 Santofimia MJ, Zhao L, Sietsma J. Microstructural evolution of a low-carbon steel during application of quenching and partitioning heat treatments after partial austenitization. Metallurgical and Materials Transactions. A, Physical Metallurgy and Materials Science. 2009;40(I):46.

6 De AK, Speer JG, Matlock DK. Color tint-etching for multiphase steels. Advanced Materials \& Processes. 2003;|61:27-31.

7 Mandal G, Ghosh SK, Bera S, Mukherjee S. Effect of partial and full austenitisation on microstructure and mechanical properties of quenching and partitioning steel. Materials Science and Engineering A. 2016;676:56-64.

8 Gorni AA, Freitas FV, Reis JSS, Silveira JHD, Cavalcanti CGL. Fatores que afetam a razão elástica de chapas grossas de aço microligado. In: Associação Brasileira de Metalurgia, Materiais e Mineração. Anais do $39^{\circ}$ Seminário de Laminação-Processos e Produtos Laminados e Revestidos; 2002; São Paulo, Brazil. São Paulo: ABM; 2002.

9 Soeiro JC Jr, Rocha DB, Brandi SD. Uma breve revisão histórica do desenvolvimento da soldagem dos aços API para tubulações. Soldagem \& Inspeção, 2013;18(2): 176-195.

10 Zhang K, Zhang M, Guo Z, Chen N, Rong Y. A new effect of retained austenite on ductility enhancement in high-strength quenching-partitioning-tempering martensitic steel. Materials Science and Engineering $A$. 20I I;528(29-30):8486-8491.

I I Wang CY, Shi J, Cao WQ, Dong H. Characterization of microstructure obtained by quenching and partitioning process in low alloy martensitic steel. Materials Science and Engineering A. 20 I0;527(I5):3442-3449.

12 Diego-Calderón I, Knijf D, Molina-Aldareguia JM, Sabirov I, Föjer C, Petrov R. Effect of Q\&P parameters on microstructure development and mechanical behaviour of Q\&P steels. Revista de Metalurgia, 20 I5;5I(I): e035.

13 Batalha RL. Envelhecimento por deformação em juntas soldadas de tubos de aço API $5 \mathrm{~L}$ X65Q sem costura [dissertação]. Ouro Preto: Universidade Federal de Ouro Preto; 2015.

14 Marques GD, Alves LGR, Roza JE, Hashimoto TM, Pereira MS. Influência do tempo de transformação isotérmica sobre as propriedades mecânicas de um aço API $5 \mathrm{~L}$ X80 multifásico. In: Anais do Congresso Brasileiro de Engenharia e Ciência dos Materiais; 2000; São Pedro, Brazil. São Paulo: IPEN; 2000.

Recebido em: 30 Ago. 2018

Aceito em: 19 Mai. 2019 